\title{
Evolução morfológica e espaçotemporal (2002 - 2015) de dunas barcana e barcanóide na planície costeira de Paracuru, Ceará, Brasil.
}

\author{
Morphological evolution and spatiotemporal (2002 - 2015) of barchan and \\ barcanoid dunes on the coastal plain of Paracuru, Ceará, Brazil.
}

\author{
MARQUES $^{1}$, J. M. R.; MEIRELES ${ }^{2}$, A. J. A. \\ matheusgeoufc@gmail.com
}

\begin{abstract}
Resumo
Zonas costeiras estão entre os ambientes mais dinâmicos do planeta. A área da planície costeira de Paracuru, Ceará, apresenta variadas morfologias, como promontório, falésias e campos de dunas móveis, nos quais esses são compostos, em grande parte, por dunas barcanóides e em uma pequena parte por dunas barcanas. As técnicas de geoprocessamento na sistematização dos dados e na elaboração dos mapas foram úteis nas análises espaçotemporais de duas dunas móveis, dentre todos os campos de dunas, nomeadas propriamente pelos autores: Duna Barcanóide e a Duna Barcana. Analisar-se-á como ocorreu o processo de migração dessas dunas, a partir do aporte teórico sobre âmbito costeiro e deslocamento de dunas. Foram definidos os fluxos de matéria e energia que se conectam e atuam diretamente nessa planície costeira, bem como o deslocamento das dunas. Os resultados apresentaram que a Duna Barcanóide obteve um deslocamento de 244 metros no total, em um período de 13 anos, e indicações de alta atuação dos fluxos morfogenéticos e a Duna Barcana teve um deslocamento de 176 metros, no mesmo período de tempo, exibindo influência dos fluxos morfogenéticos apenas para sua migração, bem como induziram a questionarmos de como o avanço das dunas irá se comportar posteriormente, a medida em que essas migram em direção à zona urbana da cidade.
\end{abstract}

Palavras-chave: Planície costeira; Campos de dunas móveis; Geoprocessamento.

\begin{abstract}
Coastal areas are in between the most dynamic environments on the planet. The area of the coastal plain of Paracuru, Ceará, presents various morphologies, such as headlands, cliffs and fields of mobile dunes, where largely barcanoids dunes and a small part by barchans dunes compose these fields. The geoprocessing techniques in the systematization of data and preparation of maps were useful in spatiotemporal analysis of two moving dunes named properly by the authors: Barcanoid Dune and Barchan Dune. It will be analyze as was how occurred the process of migration of these dunes, from the theoretical framework on coastal context and mobile dunes. The flows of matter and energy that connect and work directly in this coastal plain and the displacement of dunes have been define. The results showed that the Dune Barcanoid presented a displacement of 244 meters in total, over a period of 13 years, and high performance indications of morphogenetic flows and Barchan Dune had a displacement of 176 meters in the same period of time, showing influence morphogenetic flows only for their migration, which led us to question how the advance of the dunes will behave later, the extent to which these migrate towards the urban area.
\end{abstract}

Keywords: Coastal plain; Fields of shifting sand dunes; Geoprocessing.

\section{INTRODUÇÃO}

As zonas costeiras estão incluídas entre os ambientes mais dinâmicos existentes em nosso planeta (MARINHO \& FREIRE, 2013). São áreas onde é possível observar a interface continente-oceano-atmosfera, apresentando um equilíbrio dinâmico coordenado pelas variações energéticas dos processos naturais de diferentes escalas espaciais e temporais (CARVALHO \& 
SILVA, 2015), estando sujeita à influência de fluxos de sedimentos oriundos do sistema fluvial, que interagem diretamente com os processos litorâneos, produzindo grande quantidade de ambientes deposicionais e, consequentemente, de feições morfológicas (ROSSETTI, 2008).

A planície costeira do estado do Ceará abrange $573 \mathrm{~km}$ de extensão. É um sistema ambiental de evidente convergência dos principais fluxos de matéria e energia e concebe os sistemas de recarga e transporte de sedimentos (CLAUDINO SALES \& CARVALHO, 2014; MEIRELES, 2012; BRANCO et al., 2003). Apresenta morfogênese contínua, em virtude do constante material arenoso e eólico trabalhado pela deriva litorânea, que favorece a origem de feições morfológicas em sua extensa área (MEIRELES, 2012; CLAUDINO SALES \& PEULVAST, 2006). Tais feições apresentam-se como zona de praia, dunas móveis, paleodunas e falésias (BEZERRA \& MAIA, 2012), nas quais encontram-se sobrepostos aos sedimentos da Formação Barreiras (SOUZA, 1988), que são depósitos do Neógeno (CARVALHO et al., 2006), possuindo complexas fácies sedimentares na zona costeira, onde caracterizam-se por via de acreções eólicas, revelando extensos e comuns ambientes praiais, dunares e de falésias ao longo do litoral cearense.

A planície costeira de Paracuru, no estado do Ceará, situa-se a $70 \mathrm{~km}$ ao oeste de Fortaleza (figura 01) e representa a área de estudo deste trabalho. Tal unidade geoambiental exibe falésias, promontório e campos de dunas móveis com lagoas interdunares, funcionando como uma importante fonte de abastecimento hídrico (SOUZA, 2007). 


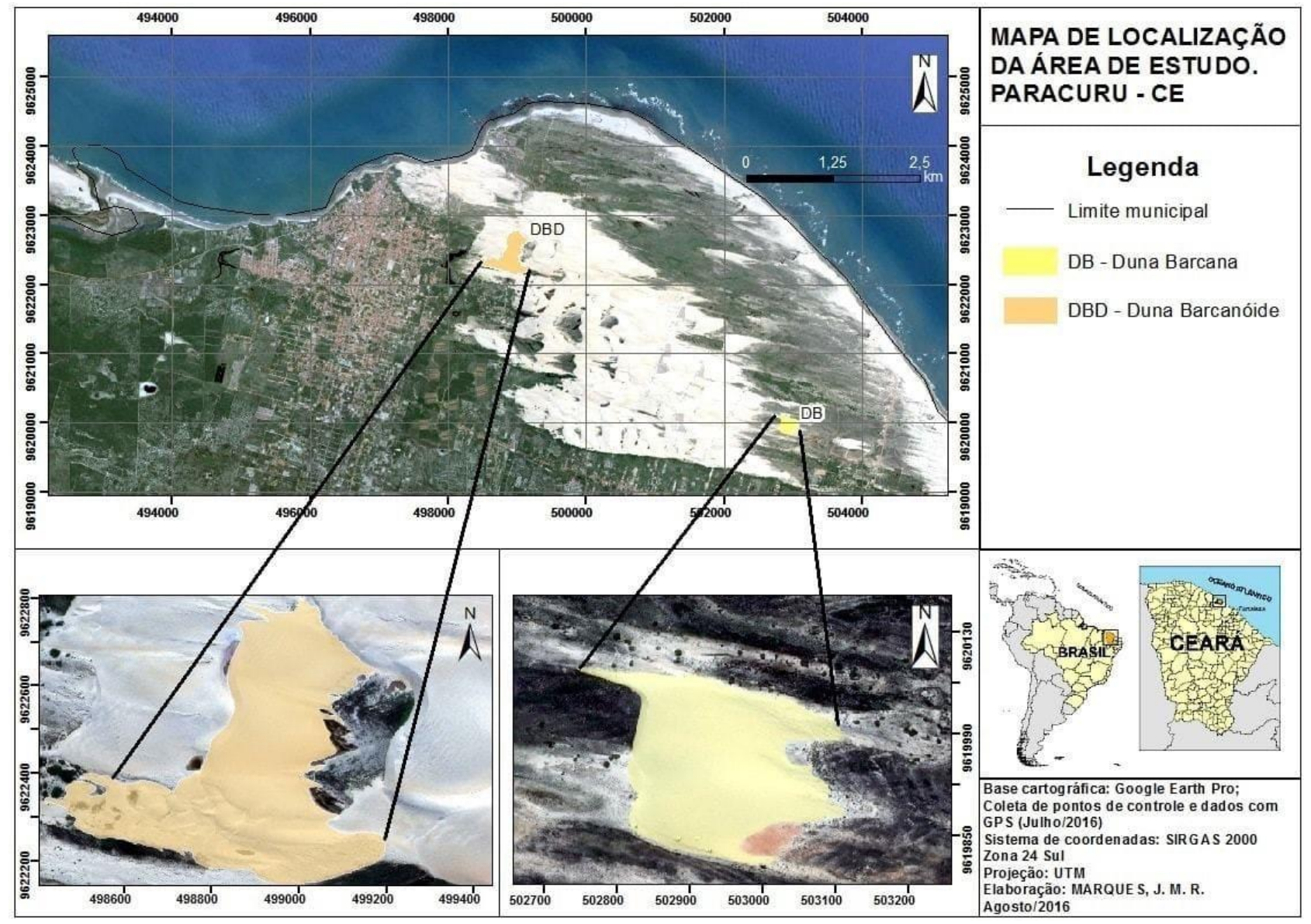

Figura 01: Localização da área de estudo e das dunas barcanóide e barcana.

Fonte: MARQUES (2016).

As dunas móveis de Paracuru expõem-se morfologicamente como barcanas, em sua maioria barcanóides (CARVALHO et al., 2006) e atualmente forma-se um campo transversal, nas quais abrangem uma área de aproximadamente $12 \mathrm{~km}^{2}$. Desse total, cerca de $4 \mathrm{~km}^{2}$ das dunas realizam o processo descrito por Tinley (1985), o bypass costeiro, chegando a atingir a praia a sotamar, onde há uma acreção de sedimentos ao oeste da cidade, em virtude do esporão aportados pelos sedimentos dunares (CLAUDINO SALES \& CARVALHO, 2014).

Os campos de dunas de Paracuru são ótimos exemplos de como ocorre a migração de dunas na planície costeira cearense, onde todos esses campos estão migrando em direção à zona urbana da cidade. Assim, entende-se que o objetivo deste trabalho é compreender a evolução morfológica e espaçotemporal de duas dunas nomeadas propriamente: "Duna Barcana" e a "Duna Barcanóide". Para tanto, irá analisar como estas migram em direção ao sentido oeste da planície, com base na literatura geomorfológica costeira presente, junto ao auxílio do geoprocessamento com a elaboração do mapeamento sistemático das dunas num período de 13 anos (2002 - 2015). 


\section{METODOLOGIA}

Para a realização desse trabalho utilizou-se, primeiramente, uma revisão bibliográfica com o intuito de caracterizar o processo de migração de dunas móveis, relacionando a granulometria, granuloseleção e a morfologia das duas dunas em questão, e também a dinâmica costeira desse ambiente. Para a sistematização da evolução espaçotemporal, adotou-se a metodologia de Pereira Filho (2014), na qual teve a aquisição de imagens multitemporais ortoretificadas do Google Earth Pro dos anos de 2002 a 2014, uma imagem de 2004 do satélite Quickbird (resolução espacial de 60cm) e uma imagem do ano de 2015 do satélite Landsat 8 ETM+ (resolução espacial de 30m), sendo necessário realizar o Processamento Digital de Imagem (PDI) somente para a imagem do satélite Landsat $8 \mathrm{ETM}+$, em virtude do tratamento e composição colorida das bandas 6, 5, 4 para interpretação e visualização. Foram coletados, em campo, os pontos de controle com GPS no sistema de projeção SIRGAS 2000 Zona 24 Sul para o georreferenciamento das dunas. A análise em geoprocessamento contou com os softwares ENVI 5.3 para o PDI e o ArcGIS 10.3 para o georreferenciamento, vetorização, sobreposição espacial e mapeamento espaçotemporal. Foi estabelecida para o mapeamento a base das dunas, estando exposta no solo ou no limite entre uma duna e outra, como em muitos casos das barcanóides. A análise das áreas e produção de gráficos foi realizada no ambiente estatístico do software $R$ (versão 3.3.1). Foi estabelecido os limites das dunas na direção leste para a representação do deslocamento espaçotemporal em metros. As duas dunas investigadas são de feição barcanóide e barcana: a primeira apresenta um grande deslocamento e indicação de grande intensidade de fluxos morfogenéticos e a segunda revela-se em uma pequena área em comparação com os campos de dunas barcanóides, porém um deslocamento aparentemente com velocidade constante.

\section{RESULTADOS E DISCUSSAO}

Percebeu-se, de acordo com as análises realizadas, que a dinâmica migratória de dunas na planície costeira de Paracuru é controlada por processos morfodinâmicos e climáticos que se conectam simultaneamente nessa planície. O estado do Ceará, apesar de estar em zona subequatorial, é regido pelo clima semiárido e tem precipitações sazonais concentradas $90 \%$ nos meses de fevereiro a junho, em virtude, sobretudo, da Zona de Convergência Inter Tropical (ZCIT) e do El Niño influenciando na variabilidade das chuvas (MAIA et al., 2005), onde podem chegar na média anual de 1350mm (CLAUDINO SALES \& CARVALHO, 2014; CLAUDINO SALES \& PEULVAST, 2006; FERREIRA, 2005; MEIRELES, 2011, 2012; ZANELLA, 2014). 


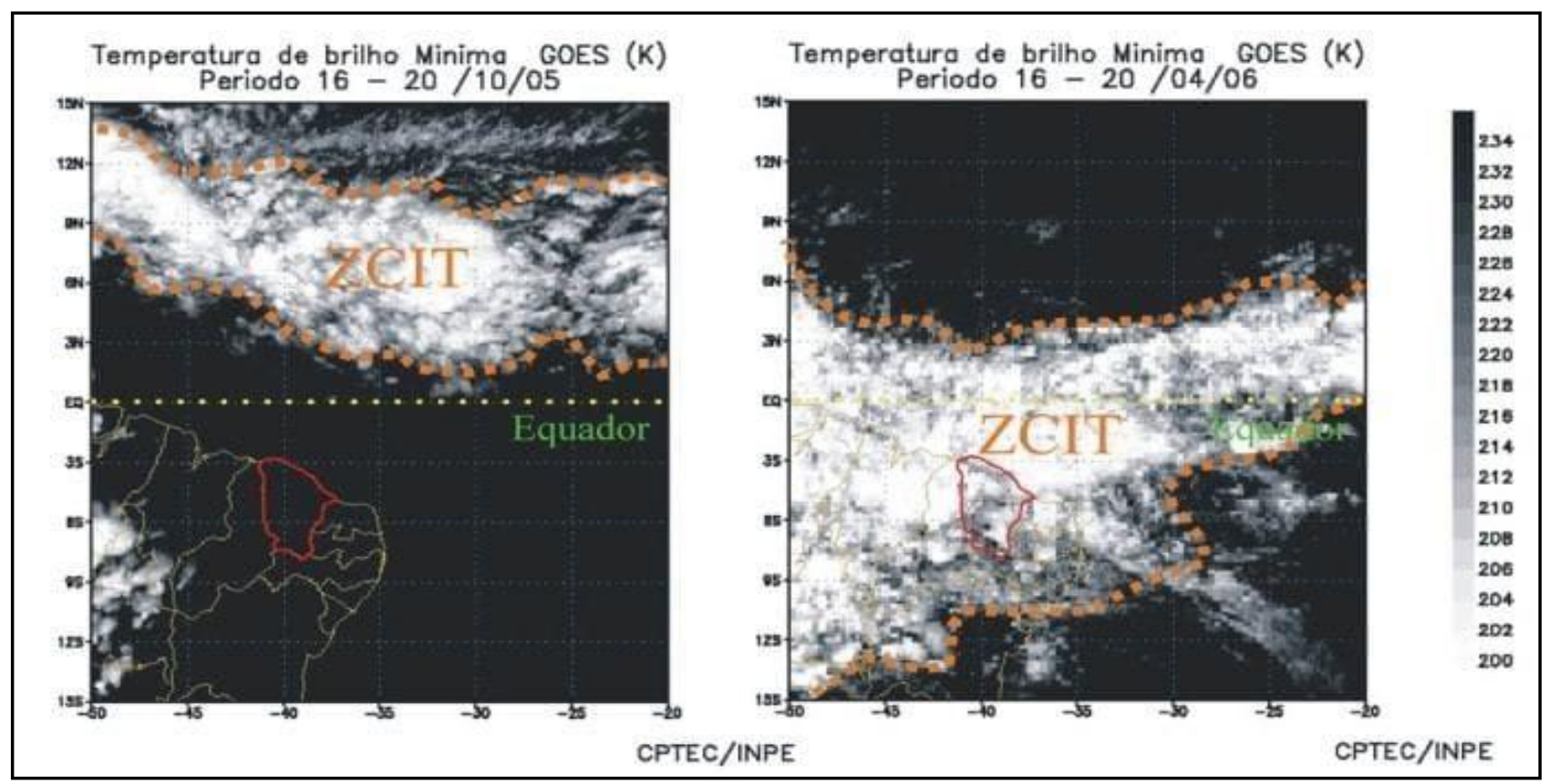

Figura 02: Variação da ZCIT no NE brasileiro, com destaque para o Ceará contornado de vermelho. Fonte: SOUZA (2007).

A ação eólica, sendo a principal componente da dinâmica migratória e da paisagem dunar, é controlada pela ZCIT e atua, predominantemente, nas direções de SE, ESE, E e NE, conforme Meireles (2011) e Souza (2007), ilustrado na figura 03. Esse evento atmosférico possui total capacidade de remoção dos sedimentos na planície costeira, agindo também na granuloseleção desses de forma em que os sedimentos que possuem granulometria fina são transportados com maior facilidade e os de granulometria grossa necessitam serem melhores trabalhados (CARVALHO et al., 2006). Assim as dunas podem lidar com alterações em sua morfometria e morfologia, onde as que eram barcanas acabam tornando-se barcanóides e vice-versa ou um achatamento, processo em que alargam suas pontas laterais e aumentam sua altura. Com relação a velocidades médias dos ventos no Ceará, no período chuvoso, (janeiro a julho) chegam a 2,5m/s, sendo incapacitados ou transportando poucos sedimentos, em virtude da forte precipitação que ocasiona a compactação dos sedimentos, além de diminuir consideravelmente a incidência eólica. No período seco (agosto a dezembro), as médias tendem a chegar de 10 a $12 \mathrm{~m} / \mathrm{s}$, possuindo total capacidade de transportar sedimentos inconsolidados pela planície (LIRA et al., 2011). 


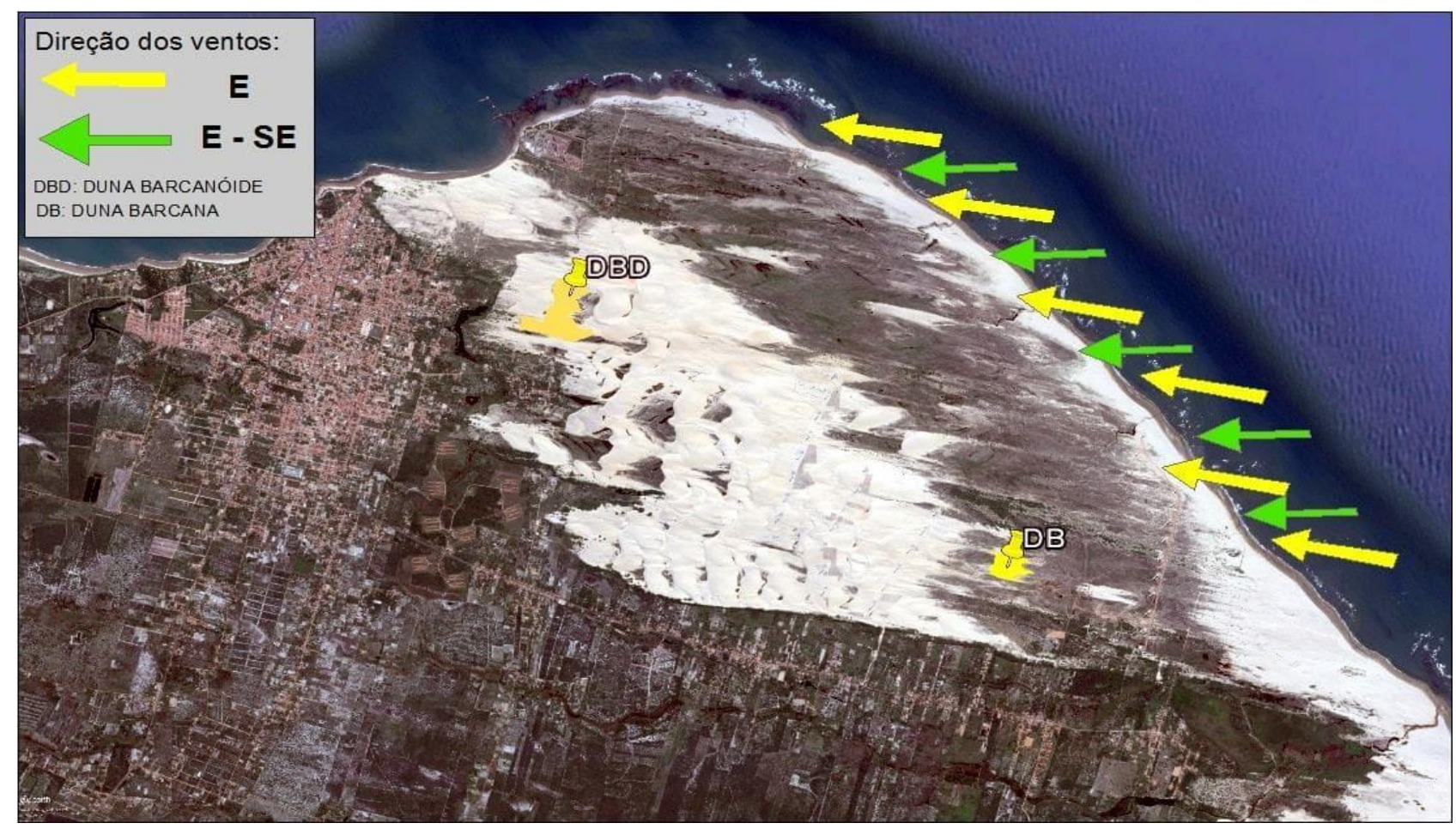

Figura 03: Direção dos ventos e migração de dunas na planície costeira em Paracuru, Ceará. Marcadas com pontos de destaque, as dunas barcanóide e barcana. Fonte: Adaptado de SOUZA (2007).

O caminhar das duas dunas em análise é caracterizado por seis fluxos de matéria e energia que se conectam e atuam de forma quase simultaneamente no espaço-tempo. Os fluxos atuantes nas dunas aqui consideradas são: (1) o processo gravitacional, que proporciona sedimentos inconsolidados para a planície, em virtude da erosão das falésias e paleofalésias da ponta de Paracuru, também favorecendo a colmatação de lagoas interdunares; (2) a deriva litorânea, na qual traz sedimentos que barram a desembocadura de sistemas fluviomarinhos, transformando-os temporariamente em sistemas lacustres. No período de maior precipitação, há o aumento de volume e energia do sistema hidrostático, em que esse rompe com os sedimentos que antes o barravam, iniciando novamente o fornecimento desses para a deriva litorânea. (3) O transporte eólico, esse já mencionado, no qual nos lembra dos fatores climáticos, mas ora adotando função de remoção de sedimentos da zona de estirâncio para o interior do continente; (4) o sistema estuarino, em que promove a formação de bancos de areia à medida que os campos de dunas migram na direção do canal do rio Curu, do lado oeste da planície, que são transportados à faixa de praia logo em seguida e (5 e 6) os fluxos fluviolagunar e aquíferos dunares, onde os campos de dunas se movem entre lagos interdunares e promovem o assoreamento parcial, ao passo da medida em que vão migrando e, em seguida, com a interação dos fluxos de matéria e energia, afloram novamente, ao mesmo tempo com a ajuda de leves variações isostáticas no nível do lençol freático (MEIRELES, 2012; CLAUDINO SALES \& CARVALHO, 2014). 
A evolução espaçotemporal da Duna Barcanóide apresenta, no período de 13 anos, uma variação de deslocamento de 176 metros, tendo uma média de deslocamento de 13,5 m/ano, como vistos na figura 04.

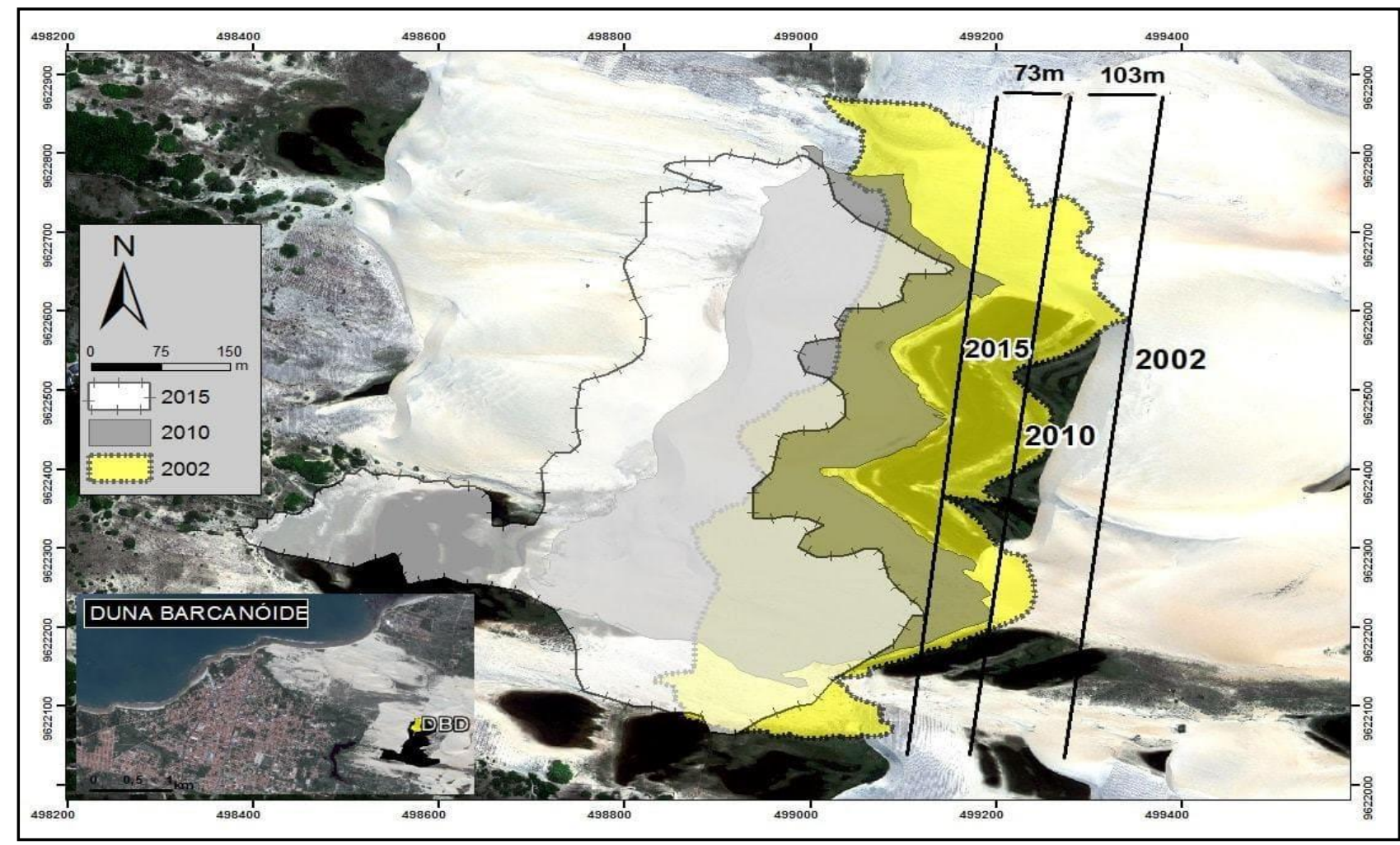

Figura 04: Evolução espaçotemporal da duna barcanóide, em Paracuru, Ceará.

Fonte: MARQUES (2016).

De início (ano de 2002), sua morfologia indica que adotara feição de barcanóide. Adiante, os sedimentos da porção oeste instalaram-se em grande quantidade nas laterais ao norte e ao sul, ocasionando uma acreção nas bordas. Assim, com a incisão e atuação dos fluxos de matéria e energia sobre si, houve um achatamento nas laterais, o que fez com que desse início a pequenos campos transversais ao sul, porém, com a delaminação dessa superfície de acreção dunar, ocorreu erosão na lateral da direção sul, em virtude sobretudo da ação eólica, o que favoreceu o assoreamento de grande parte do lago interdunar em sua frente, causando um aumento de sua área de 41,4 metros de 2010 a 2015 (figura 05). 


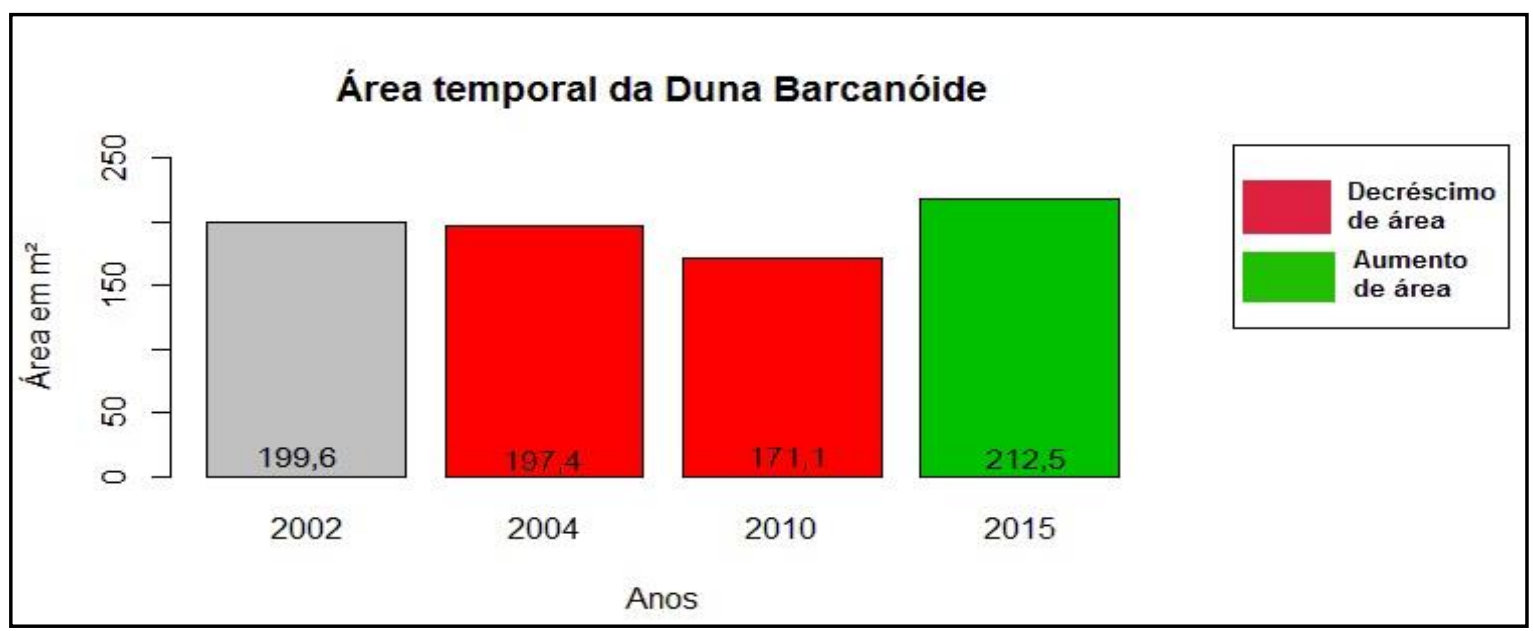

Figura 05: Gráfico da área temporal da duna barcanóide, em m². Fonte: MARQUES (2016).

A Duna Barcana em questão situa-se ao sudeste da planície costeira de Paracuru. Em sua evolução espaçotemporal, migrou 244 metros em 13 anos (2002 a 2015), dando uma média de deslocamento de $18,7 \mathrm{~m} /$ ano (figura 06)

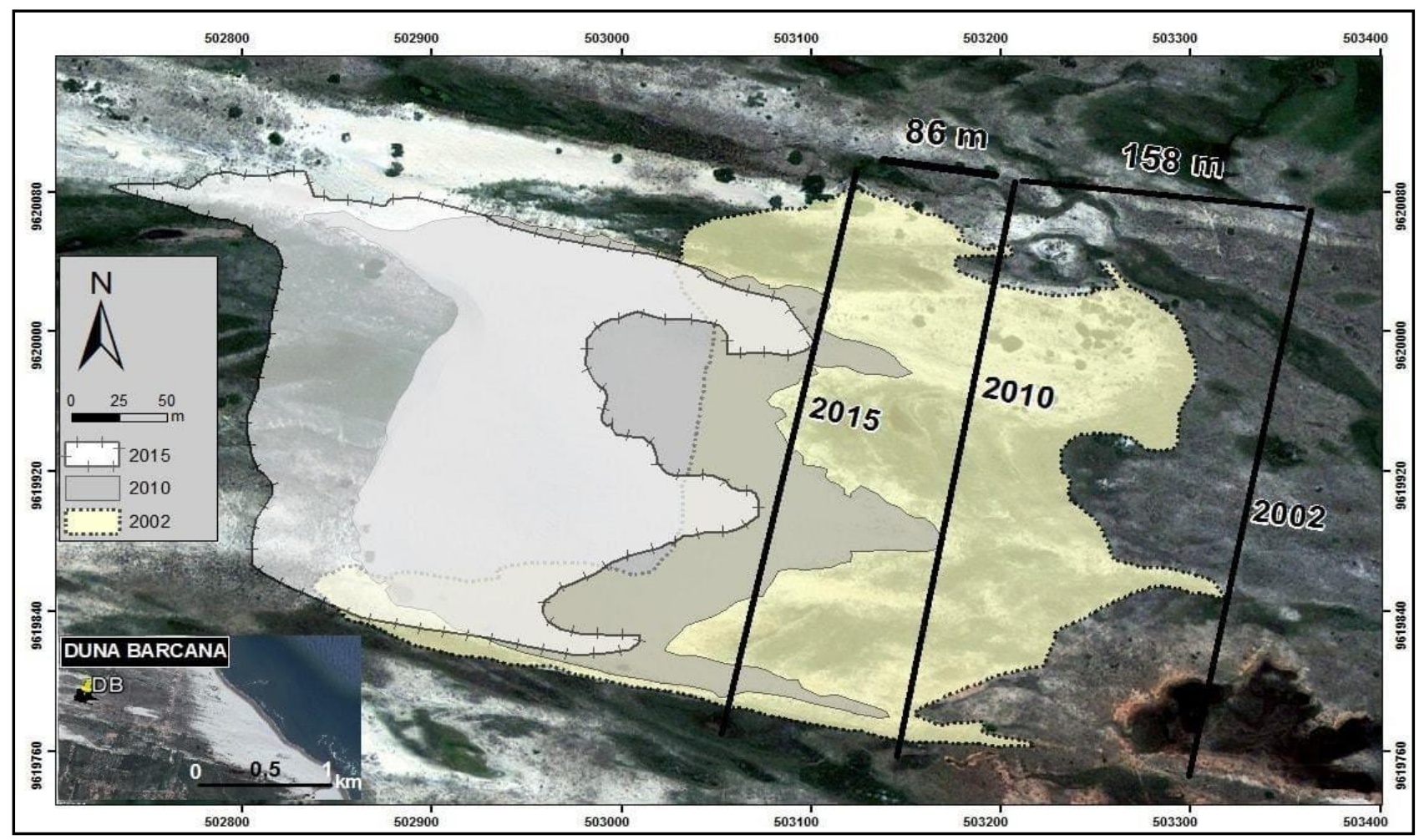

Figura 06: Evolução espaçotemporal da duna barcana, em Paracuru, Ceará.

Fonte: MARQUES (2016).

No atual momento está assoreando pequenas lagoas interdunares, que foram cobertas antes por sedimentos de dunas que já passaram, bem como a sua ponta setentrional afina-se, ocasionando um acréscimo de área (figura 07) e indicando o modo de incidência dos fluxos eólicos nessa. 


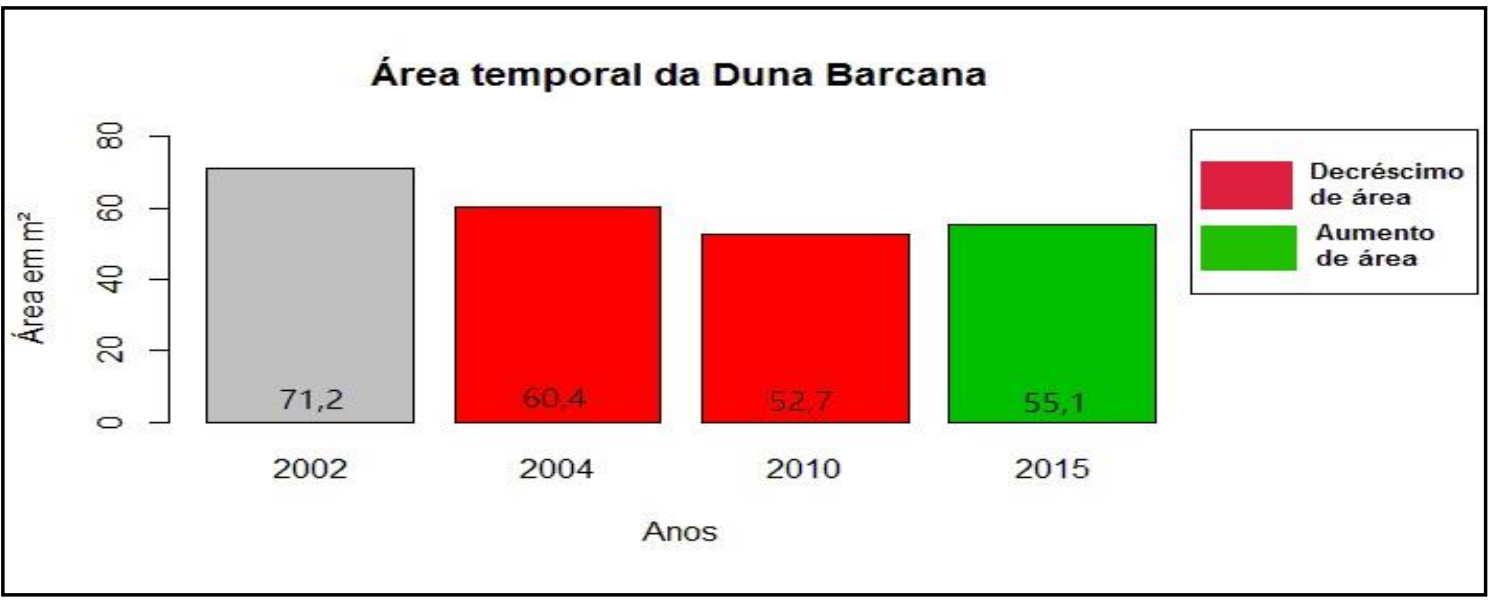

Figura 07: Gráfico da área temporal da duna barcana, em m². Fonte: MARQUES (2016).

\section{CONCLUSÃO}

As zonas costeiras são ambientes dinâmicos regidos por fluxos de matéria e energia que associam e promovem alterações em suas morfologias dunares, de falésias, praiais, linha de costa que são necessárias para o seu desenvolvimento. A planície costeira de Paracuru, Ceará, compreende-se como uma ótima representação de como essa dinâmica é influenciada em virtude de fatores externos e internos, onde geram alterações nas formas de feições morfológicas, favorecendo um ambiente de alta dinâmica em um período curto.

Dunas móveis são caracterizadas por sedimentos inconsolidados que são trabalhados a partir da deriva litorânea pelos efeitos erosivos, transportadores, deposicionais e atualmente ainda continuam lidando com esses, produzindo novas feições em um determinado espaço-tempo. Os campos de dunas da planície costeira de Paracuru migram em direção à zona urbana da cidade, ao passo em que cada vez mais se aproximam dessa, onde por certo chegará a causar danos nas infraestruturas, como soterramento de casas, em virtude da má locação urbana planejada. O geoprocessamento, no sensoriamento remoto e sistematização dos dados quantitativos e vetoriais, auxilia na exposição do ambiente como também no planejamento, no que diz respeito ao processo decisório em relação a zona urbana face a aproximação das dunas (FITZ, 2008), caso forem tomadas medidas de precaução para que não cheguem a causar danos no espaço urbano da cidade.

A Duna Barcanóide passou por alterações tanto na sua morfologia quanto na morfometria, em seu desenvolvimento no período de 13 anos, em adição a sobreposição de campos de dunas que se movem rapidamente, unindo-se a ela. O desenvolvimento da Duna Barcana ainda é recente, comparado aos campos de dunas maiores na direção norte da planície de Paracuru, visto sua dimensão e localização. Os seus deslocamentos têm como motivo, em suma, os agentes eólicos, climáticos, hidroflu viais. 


\section{REFERÊNCIAS}

BRANCO, M. P. N.C.; LEHUGEUR, L. G. O.; CAMPOS, J. E. G. Proposta de Classificação para as Feições Eólicas do Setor Leste da Região Metropolitana de Fortaleza - Ceará - Brasil. UNESP, São Paulo, Revista Geociências, v. 22, n. 2, p. 163 - 174. 2003.

BEZERRA, L. J. C.; MAIA, L. P. Caracterização sedimentológica dos Tabuleiros Pré-Litorâneos do estado do Ceará. Arquivos de Ciências do Mar. n. 45(1), Fortaleza: 2012.

CARVAlHO, R. G.; SIlvA, A. L. B. Desafios da gestão da zona costeira no Brasil. In: CARVAlHO, R. G.; PIMENTA, M. R. C. (orgs.). Gestão da Zona Costeira: estudos de casos no Nordeste do Brasil. Mossoró, RN: Edições UERN, 2015. 251 p.

CARVAlho, A. M.; MAIA, L. P.; DOMingueZ, J. M. L. Caracterização do processo de migração das dunas de Flexeiras, Baleia, Paracuru e Jericoacoara, costa Noroeste do Ceará. Arquivos de Ciências do Mar. n. 39, Fortaleza: 2006.

CLAUDINO SALES, V.; CARVALHO, A. M. Dinâmica costeira controlada por promontórios no estado do Ceará, nordeste do Brasil. Revista Geociências, vol. 33, n. 4. São Paulo: 2014

CLAUDINO SALES, V; PEULVAST, J. P. Geomorfologia da Zona Costeira do Estado do Ceará, Nordeste do Brasil. In: SILVA, J. B da; DANTAS, E. W. C.; ZANELLA, M. E.; MEIRELES, A. J. A. (orgs.). Litoral e Sertão, natureza e sociedade no nordeste brasileiro. Fortaleza: Expressão Gráfica, 2006.

FERREIRA, A. G. Principais sistemas atmosféricos atuantes sobre a região nordeste do Brasil e a influência dos oceanos Pacífico e Atlântico no clima da região. Revista Brasileira de Climatologia, Vol. 1, n. 1. 2005.

FITZ, P. R. Geoprocessamento sem complicação. São Paulo: Oficina de Textos, 2008, 160 p.

LIRA, M. A. T.; SILVA, E. M.; ALVES, J. M. B. Estimativa dos recursos eólicos no litoral cearense usando a teoria da regressão linear. Revista Geociências, Vol. 26, n. 3. São Paulo: 2011.

MAIA, L.P., FREIRE, G.S.S. \& LACERDA, L.D. Accelerated Dune Migration and Aeolian Transport During El Niño Events along the NE Brazilian Coast. Journal of Coastal Research, v. 21, n. 6. Florida: 2005. 
MARINHO, M. T. R. D.; FREIRE, G. S. S. Análise da evolução da linha de costa entre as Praias do Futuro e Porto das Dunas, Região Metropolitana de Fortaleza (RMF), estado do Ceará, Brasil. Revista de Gestão Costeira Integrada/Journal of Integrated Coastal Zone Management, Volume 13, n. 1. 2013.

MEIRELES, A. J. A. Geomorfologia Costeira: funções ambientais e sociais. 1 ed. Fortaleza: Edições UFC, 2012. 489p.

MEIRELES, A. J. A. Geodinâmica dos Campos de Dunas Móveis de Jericoacoara/CE-BR. Revista Mercator, Ano 10, n. 22. Fortaleza: 2011.

PEREIRA FILHO, N. de Sá. Análise da dinâmica-temporal (1973 a 2014) das dunas de

Jericoacoara, Ceará, Brasil. Dissertação de Mestrado apresentada ao Programa de Pós-Graduação em Geografia/Universidade Federal do Ceará, 2014, 85f.

ROSSETTI, D. F. Ambientes costeiros. In: FLOREZANO, T. G. (org). Geomorfologia: conceitos e tecnologias atuais. São Paulo: Oficina de Textos, 2008.

SOUZA, M. J. N. Contribuição ao estudo das unidades morfoestruturais do Estado do Ceará. Revista de Geologia, Fortaleza, v.1, p.73-91, 1988.

SOUSA, P. H. G. O. Dinâmica ambiental e transformações socioespaciais da orla marítma de Paracuru - Ceará. Dissertação de Mestrado apresentada ao Curso de Mestrado Acadêmico em Geografia/Universidade Estadual do Ceará, 2007, $113 \mathrm{f}$.

TINLEY, K. F. Coastal dunes of South Africa. South Africa National Scientific Programmes Report 109. Pretoria: Foundation for Research Development. Pretoria, 1985, 297p.

ZANELLA, M. E. Considerações sobre o clima e os recursos hídricos do semiárido nordestino. Caderno Prudentino de Geografia, Volume Especial, n. 36. Presidente Prudente: 2014.

\section{AGRADECIMENTOS}

Agradecemos a professora Vanda Claudino Sales (Departamento de Geografia - UFC) pelas revisões críticas e a Herbster Alencar e Samuel Pinheiro, bolsistas do PET Geografia UFC, pelas considerações.

Recebido em: 14/08/2016

Aceito para publicação em: 01/10/2016 